\title{
Interrogações sobre políticas de formação e ensino de arte nos currículos dos cursos de pedagogia
}

\author{
Janedalva Pontes Gondim \\ Universidade do Vale do São Francisco \\ Ângela Maria Dias Fernandes \\ Universidade Federal da Paraíba
}

\begin{abstract}
Resumo
0 artigo apresenta os resultados de uma pesquisa desenvolvida no programa de pós-graduação em Educação da Universidade Federal da Paraíba. A investigação objetivou analisar as contradições sociais, políticas e ideológicas presentes nos documentos institucionais sobre as políticas de formação de professores e o ensino de arte nos currículos dos cursos de Pedagogia, utilizando para tal os princípios teóricos e metodológicos da análise crítica do discurso. Foram analisadas as Diretrizes Curriculares Nacionais para o curso de Pedagogia de 2006, os projetos político-pedagógicos desses cursos nas universidades públicas da Paraíba (Universidade Federal da Paraíba - Campus João Pessoa, Universidade Federal de Campina Grande - Campus Campina Grande, Universidade Estadual da Paraíba - Campus Campina Grande) e as ementas das disciplinas relacionadas ao ensino de arte desses projetos. Apesar de as mudanças curriculares serem recentes, encontraramse concepções e modelos descontextualizados, conservadores e equivocados no que diz respeito à formação docente e ao sentido da arte, demonstrando que existe ainda um longo caminho a ser seguido na construção de propostas curriculares que estejam comprometidas com a atividade criadora do ser humano. Portanto, investir no ensino de arte e na formação do professor-pedagogo contribuiria tanto para o enriquecimento de sua formação humana, por meio da produção artística, como para a potencialização da capacidade criadora dos estudantes, conforme proclamado pelos defensores de um ensino de arte que aponte para a multiplicidade do ser humano.
\end{abstract}

\section{Palavras-chave}

Correspondência:

Janedalva Pontes Gondim

Políticas de formação docente - Currículo - Ensino de arte.

Av: Antonio Carlos Magalhães, $\mathbf{5 1 0}$

(Colegiado de Artes Visuais)

48.902-300 - Juazeiro (BA)

E-mail: janedalvagondim@hotmail.com 


\section{Inquiries on teacher education policies and art teaching in the curricula of Pedagogy courses}

Janedalva Pontes Gondim

University of Vale do São Francisco

Ângela Maria Dias Fernandes

Federal University of Paraiba

Contact:

Janedalva Pontes Gondim

Rua Alzira Coutinho de Araújo 95/602,

58052-119 - João Pessoa /PB

E-mail: janedalvagondim@hotmail.com

\section{Abstract}

The article presents the results of a study developed at the graduate program in Education of the Federal University of Paraiba. The investigation had as its objective to analyze the social, political and ideological contradictions observable in the institutional documents on the education policies for teachers and for art teaching in the curricula of Pedagogy courses, making use, for this purpose, of theoretical and methodological principles of the critical discourse analysis. The analysis included the 2006 National Curriculum Guidelines for the Pedagogy course, the political-pedagogical projects of these courses at the public universities of Paraiba (Federal University of Paraiba João Pessoa Campus, Federal University of Campina Grande - Campina Grande Campus, State University of Paraiba Campina Grande Campus), and the syllabuses of the disciplines related to the teaching of art in these projects. Although these curriculum changes are recent, the study found decontextualized, conservative, and mistaken conceptions and models regarding teacher education and the meaning of art, demonstrating that there is still a long way ahead in the construction of curriculum proposals committed to the creative activity of the human being. Therefore, investing in the teaching of art and in the formation of the teacher-pedagogue would contribute both to enrich their human formation through the artistic production, and to stimulate the creative capacity of the students, as proclaimed by the defenders of an art teaching that points toward the diversity of the human being.

\section{Keywords}

Teacher education policies - Curriculum - Art teaching. 


\section{Caminhos trilhados na construção da pesquisa}

As discussões acerca da educação e das políticas de formação docente vêm mobilizando pesquisadores das diversas áreas do conhecimento com o intuito de repensar as bases da educação na conjuntura mundial. Diante disso, observamos a obrigatoriedade do ensino de arte presente na legislação educacional, ocasionada pelas várias reformas que o governo brasileiro vem promovendo desde a década de 1990, com o objetivo de acompanhar as deliberações de acordos internacionais para a melhoria da qualidade na educação, interpeladas pela globalização e pelo neoliberalismo.

Entre essas mudanças, analisamos as políticas de formação docente e de currículo nos dispositivos legais que regulamentam a educação em nosso país, como a Lei de Diretrizes e Bases da Educação Nacional - LBDEN 9.394/96 - e a Resolução do Conselho Nacional de Educação - CNE/CP n ${ }^{\circ}$. 1, de 15 de maio de 2006, que institui as Diretrizes Curriculares para o curso de graduação em Pedagogia (DCN).

Em relação à formação docente para os anos iniciais, as DCN/2006, em seus artigos, validam as reivindicações de arte-educadores pertinentes à presença do ensino da arte na escolarização inicial, assim como indicam a necessidade de uma formação docente marcada pelo compromisso com o desenvolvimento estético, criador e artístico do ser humano.

Procuramos, nesta pesquisa, compreender e explicar a dinâmica do tema em estudo para responder à seguinte questão: Como $o$ ensino de arte é concebido nos discursos do respaldo institucional legal das politicas de formação docente acerca dos currículos dos cursos de Pedagogia? Para tanto, analisamos as contradições sociais, políticas e ideológicas presentes nos documentos institucionais produzidos para esse fim, como as DCN/2006, os projetos político-pedagógicos dos cursos de Pedagogia de universidades públicas da
Paraíba (UFPB - Campus João Pessoa, UFCG - Campus, Campina Grande, UEPB - Campus Campina Grande) e as ementas das disciplinas relacionadas ao ensino de arte desses projetos.

Os documentos foram submetidos à análise crítica do discurso, entendendo a língua como um produto socioideológico, por refletir e refratar a realidade na medida em que produz um domínio semiótico (BAKHTIN, 1997).

Para significar a linguagem como prática social (FAIRCLOUGH, 2001), empregaremos o termo "discurso", concebendo-o como uma prática não apenas de representação, mas de significação do mundo, constituindo e construindo um campo de significações.

Acreditamos que os resultados suscitados pela pesquisa podem desencadear processos de reflexão sobre a formação inicial de professores nos cursos de Pedagogia e a ampliação das concepções discursivas acerca da complexidade do ensino de arte na formação do professor-pedagogo.

\section{O ensino de arte e as políticas educacionais no Brasil}

Atualmente, observam-se, nas políticas educacionais, reformulações curriculares na educação básica e na formação docente, demonstrando uma aparente preocupação com o ensino de arte, como veremos nas análises realizadas no decorrer do texto. Essas reformulações estão no bojo de um contexto maior de mudanças na estrutura social e política que deflagraram novos rumos para a educação em nível mundial.

0 processo de globalização e o neoliberalismo impuseram uma nova organização social e política orientada pelo mercado. De fato, a política neoliberal prevê o progressivo desmantelamento do Estado como agência produtora de bens e serviços e como aparelho institucional orientado para garantir e promover os direitos da cidadania (GENTILI, 1999, p. 106). Para Gentili (1998), isso significa que a educação deixa de ser compreendida como 
direito para ser tratada como oportunidade, variando segundo o mérito e a capacidade dos consumidores.

Segundo Ball e Bowe (1998), “o foco no professor tem sido importante na produção de políticas curriculares, não apenas visando a controlá-los com efetividade, como também para induzi-los a aceitar essas políticas" (p. 108, destaque dos autores).

Na presente pesquisa, é relevante a observação de que as disputas entre as divergentes posições sobre a identidade e a agência de formação do pedagogo ocasionaram negociações que culminaram com a homologação das Diretrizes Curriculares Nacionais (DCN) para o curso de Pedagogia, através do Parecer CNE/CP n. 5, de 13 de dezembro de 2005, do Parecer CNE/CP n. 3/2006 e da Resolução n. 1, de 2006. Diante desse cenário, discutimos outro mecanismo de intervenção do Estado na atividade docente no que diz respeito, especificamente, às políticas de currículo e à obrigatoriedade do ensino de arte na educação básica.

Observamos que a nova LDBEN 9.394/96, ao estabelecer a obrigatoriedade da arte na educação básica não como atividade, mas como pertencente ao conjunto de conhecimentos inerentes ao processo educacional, expressou, do ponto de vista legal e político, a conquista dos arte-educadores, que reivindicavam o acesso desse conhecimento aos alunos do ensino básico como uma possibilidade de desenvolvimento social e cultural (BARBOSA, 2005b).

No entanto, no texto da lei, não fica claro de que forma isso será viabilizado nas instituições escolares. Vale salientar que a promulgação da LDBEN/96 envolveu campos ideológicos e políticos que se confrontaram para definir os rumos da educação brasileira.

Diante desse emaranhado de ações e deliberações, questionamo-nos sobre o teor político-ideológico que está posto, por entendermos que é necessário compreender a trama que tece as políticas de currículo no contexto atual. Para tanto, partimos do pressuposto de que o currículo se constitui como um espaço de lutas simbólicas de saber-poder e, nesse caso, de regulação sobre o que deve ser ensinado nas instituições educacionais e como esse ensino é experienciado. Segundo Apple (1995), não se trata "apenas" de uma questão educacional, mas de uma questão intrinsecamente ideológica e política. Na construção do território curricular, destaca-se também a centralidade da cultura (CANCLINI, 1998; HALL, 1997; MACED0, 2006a) como campo de disputa que incorpora valores de mercado, mas também alternativas que a tornam política por excelência. Macedo (2006b, p. 286) defende uma leitura do currículo que seja capaz de pensar o espaço-tempo da política como um cruzamento entre características globais do capitalismo e especificidades locais, em um processo que envolve hibridismo cultural ${ }^{1}$. Nesse sentido, entender o currículo como campo da política cultural possibilita a desconstrução de uma visão naturalizada e tecnicista em que os discursos e as narrativas são práticas que modelam o que chamamos de "realidade", instituindo sentido, hierarquizando e articulando relações específicas de significação. 0 processo de significação é um processo social de conhecimento e, nesse aspecto, “os saberes são sempre mediados pela linguagem, cujos campos de realização não estão isentos de relações de poder" (COSTA, 1999, p. 51).

\section{Análise dos currículos dos cursos de pedagogia na Paraíba:} a arte na formação do pedagogo

\section{Aspectos teóricos e metodológicos para análise crítica do discurso}

A preocupação com a formação de professores dos anos iniciais do ensino fundamental para o ensino de arte se deve aos fatos justificados anteriormente. Esclarecemos, no

1. Néstor Canclini (1998, p. XIX) entende que a expressão hibridismo cultural abrange "processos socioculturais nos quais estruturas ou práticas discretas, que existiam de forma separada, combinam-se para gerar novas estruturas, objetos e práticas". 
entanto, que a análise de discurso sobre o ensino de arte nos currículos dos cursos de Pedagogia é apenas um recorte que, de maneira alguma, esgota a compreensão do tema estudado. Por essa razão, realizamos a pesquisa nos currículos em vigor no ano de 2009 dos cursos de Pedagogia de universidades públicas da Paraíba ${ }^{2}$, responsáveis pela formação de professores que lecionarão em escolas públicas e particulares da região. Analisamos os documentos institucionais, principalmente as DCN/2006, o projeto político-pedagógico dos cursos de Pedagogia das universidades investigadas e as ementas das disciplinas relacionadas ao ensino de artes nesses documentos.

Utilizamos a análise do discurso, focalizando as construções ideológicas presentes nos textos oficiais sobre a formação docente e o ensino de arte nesses currículos. Nessa perspectiva, todo discurso é uma construção social, não individual, e só pode ser analisado considerando-se seu contexto histórico-social, suas condições de produção. Significa, ainda, que o discurso reflete uma visão de mundo determinada, necessariamente vinculada à do(s) seu(s) autor(es) e à sociedade em que vive(m).

Por essa razão, encontramos na Análise Crítica do Discurso (ACD) os pressupostos teóricos e metodológicos que procuramos para subsidiar nossas análises. Portanto, nossa opção por essa linha de pensamento se deve ao fato de que ela considera a língua como expressão das relações e das lutas sociais, que veicula e sofre o efeito dessas lutas, servindo, ao mesmo tempo, de instrumento e de material (BAKTHIN, 1997, p. 17).

Nessa concepção, a linguagem, entendida como uma prática social, contribui efetivamente para a construção da realidade. Assim, consideramos a ACD como um enfoque teórico e metodológico que se ocupa fundamentalmente de análises que dão conta das

2. Universidade Federal da Paraíba - Campus I João Pessoa, Universidade Federal de Campina Grande - Campus Campina Grande e Universidade Estadual da Paraíba - Campus Campina Grande. relações de dominação, discriminação, poder e controle, na forma como se manifesta através da linguagem (WODAK, 2003). Nessa perspectiva, a linguagem é um meio de dominação e de força social que serve para legitimar as relações de poder estabelecidas institucionalmente.

Em relação à análise dos documentos, partimos do pressuposto de que eles expressam uma silenciosa disputa, atravessada no e pelo currículo, cuja política cultural (COSTA, 1999) evidencia alguns conhecimentos em detrimento de outros, como ocorre na delimitação das concepções sobre arte e seu ensino nos currículos dos cursos de Pedagogia. As decisões e prescrições relativas ao currículo dos cursos de Pedagogia estão estreitamente vinculadas a estruturas de poder e dominação. Isso faz dos cursos de formação docente um espaço político no qual os embates epistemológicos e éticos se efetivam.

Não obstante, trazemos essa discussão do currículo como política cultural também para o âmbito das universidades, tendo em vista que a maioria dos estudos realizados até o momento nessa área focaliza os embates no espaço da educação básica.

\section{As DCN e a identidade do pedagogo: marcadores} discursivos e ideológicos

A identidade é entendida, neste trabalho, sobretudo, como uma construção processual das atividades sociodiscursivas das quais participamos como sujeitos sociais, históricos e culturais. 0 estudo das identidades ganha força na pós-modernidade, em que afloram as mudanças culturais, sociais, econômicas, políticas e tecnológicas.

Partimos do pressuposto de que o discurso é um espaço privilegiado de construção das identidades sociais (MOITA LOPES, 2003). $\mathrm{Na}$ atualidade, o professor-pedagogo tem assumido diferentes papéis na sociedade, e isso vem alterando o sentido de ser professor e seu campo de atuação. 
Posto isso, fica claro que hoje é preciso entender identidade como um construto plural, já que é constituída de maneira fragmentada, contraditória e em fluxo (MOITA LOPES, 2003). Sendo assim, a partir da leitura das DCN acerca da constituição discursiva sobre a identidade do pedagogo, encontramos algumas contradições sociais e políticas, as quais foram organizadas em três subtemas: a) perspectiva da racionalidade técnica; b) interculturalidade como política focalizadora e c) lugar da arte na formação do professor-pedagogo.

Entre os artigos analisados, selecionamos alguns que expressam a perspectiva predominante de formação docente presente nas Diretrizes Curriculares Nacionais que, no nosso entendimento, correspondem à racionalidade técnica, como observado a seguir:

0 estudante de Pedagogia trabalhará com um repertório de informações e habilidades composto por pluralidade de conhecimentos teóricos e práticos, cuja consolidação será proporcionada no exercício da profissão, fundamentando-se em princípios de interdisciplinaridade, contextualização, democratização, pertinência e relevância social, ética e sensibilidade afetiva e estética. (DCN, art. 3º, 2006, p. 1)

Inicialmente, destacamos, nesse enunciado, as palavras informações e habilidades, cuja utilidade se dará no exercício da profissão docente.

As palavras, segundo Bakthin (1997), "são tecidas a partir de uma multidão de fios ideológicos e servem de trama a todas as relações sociais em todos os domínios” (p. 41). A palavra informações, destacada nesse enunciado, carrega o significado utilitarista e fragmentado no contexto atual das questões educacionais, demonstrando o domínio ideológico que se contrapõe a uma visão mais global e política do ato educativo.

Ainda sobre esse artigo, percebemos que, embora expresse uma luta ideológica em que prevalece a perspectiva neoliberal de formação docente enfatizada pela racionalidade técnica, o evento discursivo é interpelado por outros discursos provenientes de uma concepção progressista, como as palavras interdisciplinaridade, contextualização, democratização, pertinência e relevância social, além de ética e sensibilidade afetiva e estética.

A noção de poder como hegemonia é entendida por Fairclough (2001) com base nas ideias de Gramsci (1989). 0 autor ressalta que

[...] a hegemonia é um foco de constante luta sobre pontos de maior instabilidade entre classes e blocos para construir, manter ou romper alianças e relações de dominação/ subordinação, que assumem formas econômicas, políticas e ideológicas. (p. 122)

Percebemos que, embora haja um discurso hegemônico em relação à política neoliberal, outros discursos disputam o domínio semiótico da formação do pedagogo, o que significa a existência de um embate de forças político-ideológicas e de uma dinâmica própria que permeiam os textos legais sem, com isso, modificar seu objetivo social. Sobre esse aspecto, Bakthin (1997) afirma que o discurso citado "conserva sua autonomia estrutural e semântica sem nem por isso alterar a trama linguística do contexto que o integrou" (p. 144).

A presença de outros discursos (interdiscursividade) no texto demonstra o movimento dialético ao qual a linguagem é submetida, na medida em que recontextualiza significados oriundos de outros domínios ideológicos.

Sobre a questão da diversidade, observa-se a tentativa de responder à complexidade das relações existentes no processo educacional na formação dos sujeitos apontados pela contemporaneidade. Entretanto, destacamos a expressão que inicia o evento discursivo:

Demonstrar consciência da diversidade, respeitando as diferenças de natureza am- 
biental-ecológica, étnico-racial, de gêneros, faixas geracionais, classes sociais, religiões, necessidades especiais, escolhas sexuais, entre outras. (DCN art. 5º, item X, 2006, p. 2)

Demonstrar consciência da diversidade representa uma passividade diante de algo que está exterior, como se demonstrar consciência da existência da diversidade já fosse suficiente para garantir sua consideração no processo educacional democrático. Ademais, a ideia de diversidade, conforme o enunciado, não admite a possibilidade de que as diferenças sejam compreendidas como constituidoras e constituintes dos sujeitos como um todo.

Dando continuidade a esse tema, no próximo artigo temos evidenciadas a diversidade e a multiculturalidade da sociedade brasileira, expressas na escolha dos estudos básicos. Vejamos:

A estrutura do curso de Pedagogia, respeitadas a diversidade nacional e a autonomia pedagógica das instituições, constituir-se-á de: I - um núcleo de estudos básicos que, sem perder de vista a diversidade e a multiculturalidade da sociedade brasileira, por meio do estudo acurado da literatura pertinente e de realidades educacionais, assim como por meio de reflexão e ações críticas, articulará. (DCN art. 6 ${ }^{\circ}$, inciso I, 2006, p. 3)

Nesse evento discursivo, subentende-se que há um foco principal na formação e que a diversidade e a multiculturalidade são aspectos secundários, e não fundantes, como defendido pelos estudos da diferença. Essa análise é possível de ser localizada, na estrutura do texto, na expressão sem perder de vista, evidenciando a contradição ideológica presente no discurso analisado.

0 aspecto do multiculturalismo aqui empreendido remete à problemática de educação intercultural emergente com a globalização e reivindicada por demandas marginalizadas da sociedade. Em geral, o chamado "multiculturalismo" apoia-se em um vago e benevolente apelo à tolerância e ao respeito para com a diversidade e a diferença, que tende a ser naturalizada, cristalizada, essencializada. É preciso que a diferença não seja entendida unicamente como resultado, mas como um processo em que tanto a identidade quanto a diferença são produzidas por atos de criação linguística (SILVA, 2000), somos nós que as fabricamos, no contexto das relações culturais e sociais.

A presença de temas que envolvem a cultura nas políticas educacionais está centrada na perspectiva de regulação e de controle dos grupos marginalizados historicamente pelo colonialismo. Primeiramente, as ações focalizam esses grupos dando a impressão de valorização de sua identidade cultural. Em seguida, mantêm as forças de dominação, através de mecanismos de produção e de circulação de identidades desejadas, isto é, trata-se de um jogo ambíguo de liberdade e de repressão.

Os efeitos sociais das contradições oriundos do embate ideológico podem ser observados na produção dos discursos sobre a diversidade, como analisado a partir do art. $6^{\circ}$. Embora o texto das DCN mencione que os currículos dos cursos devem respeitar a diversidade nacional e a autonomia pedagógica das instituições, o mesmo é contradito, uma vez que, no final do curso, há uma prova em nível nacional (Enade) para avaliar o desempenho dos alunos, dos cursos e das instituições, na perspectiva de controlar e normatizar o ensino superior brasileiro.

Nesse momento, abordamos o lugar que a arte ocupa nas análises sobre a construção da identidade do professor-pedagogo. Para tanto, destacamos o seguinte artigo:

Ensinar Língua Portuguesa, Matemática, Ciências, História, Geografia, Artes, Educação Física, de forma interdisciplinar e adequada às diferentes fases do desenvolvimento humano. (DCN art. 5, item VI, 2006, p. 2) 
0 ensino de arte é colocado no mesmo nível das outras áreas do conhecimento, revelando a conquista política de concebê-la como conhecimento necessário ao desenvolvimento do sujeito, incorporando-a ao currículo da educação básica.

Conforme Tourinho (2007), "filosofia, ensino religioso e educação física, além da Arte, são exemplos de disciplinas com longa história de lutas" (p. 30). Primeiro, pela conquista de espaço e, segundo, pela manutenção e ampliação desse espaço e de tempo na escola.

Então, se, por um lado, temos a obrigatoriedade de colocar o ensino de arte na educação básica como uma conquista política, por outro, temos implicações dessa institucionalização como uma forma de regular seu potencial questionador através de uma política de formação docente ambígua.

Além da conquista política em relação ao ensino de arte nos anos iniciais, abre-se uma discussão acerca da especificidade da arte e da formação do profissional responsável por essa disciplina. A questão está no fato de que, com a obrigatoriedade do ensino da arte na educação básica e a regulamentação que indica que o professor-pedagogo licenciado para os anos iniciais de escolarização deve também ensinar arte, aparentemente, temos a solução para a defasagem desse ensino na escolarização inicial. Entretanto, essa atitude pode ter outras interpretações ou consequências: a obrigatoriedade do ensino de arte na educação básica abre espaço para a atuação do professor de arte, como é o caso do município de João Pessoa, que, através da Resolução 009/2006 $\mathrm{CME}$, tornou obrigatório o ensino de arte em todas as séries do ensino fundamental com a presença de professores habilitados nas diferentes linguagens artísticas.

No entanto, essa não é a realidade dos municípios brasileiros, pois, quase sempre, na educação infantil e nos anos iniciais do ensino fundamental, são os professores-pedagogos encarregados de ministrar essa disciplina, e não o professor de arte.
0 ensino de arte na formação do pedagogo pode também possibilitar que ele desenvolva condições teórico-metodológicas para que possa se constituir como apreciador e seja capaz de mediar aprendizagens em arte de forma consistente, além de contribuir para o enriquecimento de sua formação humana, por meio da aprendizagem da arte, o que favoreceria a potencialização da dimensão criadora do ser humano (FERRAZ, FUSARI, 2009).

Em relação aos aspectos discutidos sobre a identidade do professor-pedagogo produzidos com base nas análises das DCN, concordamos com Moita Lopes (2003), quando afirma que a identidade social do indivíduo é construída em práticas discursivas. Nesse sentido, enfatiza a autora, "as instituições e as coletividades operam na legitimação institucional, cultural e histórica de certas identidades sociais, enquanto outras são tornadas ilegítimas, destruídas, encarceradas, estigmatizadas, silenciadas" (p. 21).

Entendemos, então, que é pertinente retomar a ideia de que a identidade do professor-pedagogo se constrói socialmente e, por isso, merece ser problematizada nos cursos de formação docente, especialmente quando essa formação envolve a produção de subjetividades críticas e criativas, o que pode ser compreendido como um dos propósitos do ensino de arte.

\section{0 currículo do curso de Pedagogia: uma construção político-cultural}

Neste trabalho, apropriamo-nos da noção de currículo como um "artefato cultural", expressão com a qual tentamos tangenciar questões que envolvem poder e cultura, pois as teorias, as diretrizes e as práticas envolvidas no currículo não são técnicas, mas intrinsecamente éticas e políticas.

Compreender a concepção de projeto político-pedagógico como campo da política cultural corresponde a discutir as vinculações entre cultura e educação na produção, circulação e consolidação de significados, como 
espaços privilegiados de concretização da política de identidade (COSTA, 1999). Nessa perspectiva, os Projetos Político-pedagógicos (PPP) dos cursos de Pedagogia das universidades públicas da Paraíba foram analisados levando-se em consideração que as reformulações oriundas das DCN para a formação do pedagogo, manifestadas nos PPP, apontam para uma concepção de currículo em que estão em jogo os objetos, as teorias e os valores que legitimam a sociedade atual, sendo resultado de seleção, tensões, conflitos, concessões culturais, políticas e econômicas que organizam e desorganizam uma sociedade.

Procuramos acentuar a importância de se interrogar sobre a conexão entre linguagem e poder a fim de compreender como a teoria curricular, como forma de autoridade textual, legitima determinada prática discursiva e concebe a arte na formação do pedagogo.

Os documentos analisados (PPP) dos cursos de Pedagogia aqui focalizados apresentam, em seu texto inicial, um relato do curso em nosso país, a conjuntura histórico-política que deu origem às regulamentações legais para sua criação e o funcionamento até os dias atuais. Observa-se que, na produção ou reformulação dos PPP, três elementos constituíram esse espaço de disputa: a) as orientações de base legal; b) as recomendações propostas pela Associação Nacional pela Formação dos Profissionais da Educação (Anfope) e pelo Fórum de Diretores das Faculdades/Centros de Educação das Universidades Públicas Brasileiras (Forumdir) ${ }^{3}$; e c) a demanda social e cultural.

Considerando as orientações de base legal que justificam as reformulações curriculares presentes nos PPP dos cursos de Pedagogia, observamos os contextos para a produção

3. A Anfope e o Forumdir representam, nos últimos vinte anos, o movimento de educadores brasileiros, mediante ações organizadas e historicamente constituídas em defesa de uma educação de qualidade socialmente comprometida com a ética e com a democracia. Dentre suas principais conquistas, destacamos: a docência como base formativa, não admitindo a formação exclusiva de especialistas como prescreve a LDBN; a adoção de uma base comum nacional como norteadora das reformulações curriculares dos cursos que formam professores e como instrumento de luta em defesa da valorização dos profissionais da educação. de políticas descritas por Ball (1998): o de influência, em que, normalmente, as definições políticas são iniciadas e os discursos políticos são construídos; o de produção dos textos das políticas, que tem uma relação simbiótica com o primeiro contexto; e o da prática, em que a política não é simplesmente implementada, mas recriada por processos de recontextualização.

Essa leitura compreende que os autores das políticas não podem controlar todos os sentidos, mas agem buscando limitar as possíveis leituras, visando a realização daquela assumida como correta. Esse processo de controlar os sentidos disponíveis à leitura não pode ser realizado de forma apenas coercitiva ou somente com base no estímulo via financiamentos oriundos dos governos federal, estadual e municipal. São necessários discursos que justifiquem e legitimem a proposta curricular a ser desenvolvida por intermédio da incorporação de outras vozes, como as propostas da Anfope e do Forumdir, por exemplo.

A partir dessa observação, das influências e da apropriação de outras vozes para a legitimação da ação política, tomamos por suporte a perspectiva da ACD, em que se compreende que, muito raramente, um texto é resultado do trabalho de apenas uma pessoa. As diferenças discursivas são negociadas nos textos; elas são regidas por diferenças de poder que são, elas mesmas, em parte, codificadas e determinadas pelo discurso e pelo gênero (WODAK, 2003).

A preocupação com o poder como condição central da vida social volta-se não só para a noção das lutas pelo poder e pelo controle, mas também para a intertextualidade e a recontextualização de discursos que competem entre si. Dessa maneira, as reformulações curriculares propostas pelas DCN são incorporados no texto dos PPP dos cursos de Pedagogia não de forma verticalizada, mas hibridizada. Trata-se de ver a produção dos documentos em estudo (DCN e PPP) como processos capilares, ambivalentes, celebrações móveis presentes nos discursos, nos jogos de linguagem, ficando 
inteligivel falar de currículo como uma prática cultural discursiva e, portanto, produtora de identidades.

É importante frisar que as Diretrizes Curriculares Nacionais apontam para uma homogeneização das licenciaturas, enquadrando-as em uma formação profissional pautada em uma política da racionalidade técnica. Porém, é necessário entender os currículos como híbridos culturais que, segundo Macedo (2006a), são práticas ambivalentes que incluem o mesmo e o outro num jogo em que nem a vitória nem a derrota jamais serão completas, pois, nesse híbrido, que é o currículo, tramas oblíquas de poder tanto fortalecem certos grupos como potencializam resistências (p. 290).

É por meio de instituições diversas que o poder central busca construir mecanismos simbólicos de legitimação de seus discursos e o faz, especialmente, por meio da apropriação de discursos legitimados socialmente entre diferentes grupos sociais, como, por exemplo, as orientações de base legal, as entidades representativas da classe do professorado e as universidades. Assim, apesar das múltiplas influências sobre os textos, apenas algumas são reconhecidas como legítimas. Sob a ótica de Bernstein (1996), apenas algumas vozes são ouvidas, enquanto outras são silenciadas. Os sentidos, porém, são produtos tanto do que se ouve quanto do que é silenciado.

0 campo de atuação do pedagogo centrado na docência é fruto de disputas históricas. Relembramos o processo que ocorreu no país, na definição da política de formação de professores, no período de regulamentação da atual Lei de Diretrizes e Bases da Educação Nacional, a partir da qual muitos embates ocorreram entre pesquisadores, professores e representantes da oficialidade, em torno de diferentes concepções e propostas de formação docente.

Nesse debate, também foi possível perceber a influência de organismos internacionais, em especial o Banco Mundial, a Unesco, entre outros, configurando um processo complexo de influências recíprocas entre diferentes sujeitos e instâncias diversas do sistema educacional, caracterizado pela recontextualização e hibridização de diferentes concepções, textos e fragmentos de textos (BALL, 1998; BALL; BOWE, 1998).

$\mathrm{Na}$ disputa ideológica sobre o campo de atuação do pedagogo, observamos claramente a articulação entre o discurso da docência, defendido pela Anfope, e o discurso neoliberal de gestão, que revela o movimento dialético do exercício do poder a partir do qual as forças antagônicas negociam e fazem alianças, em que o poder, segundo Canclini (1998), é oblíquo e contingente.

Concepções de arte e ensino de arte: uma análise das ementas dos cursos de pedagogia da Paraíba

Destacamos no texto da ementa da disciplina Ensino de Arte do Curso de Pedagogia da UFPB - Campus I João Pessoa, reproduzido abaixo, a concepção de arte, cuja importância na educação se fundamenta como processo de criação e ensino.

Conteúdos e aspectos metodológicos do ensino de Arte-educação na educação infantil e nas séries iniciais no Ensino Fundamental. A importância da Arte na educação como processo de criação e de ensino. Vivência de diferentes linguagens da Arte. A música, a pintura e o teatro como facilitadoras da aprendizagem. (PPP/PEDAGOGIA UFPB, 2006, p. 31)

0 valor atribuído à arte, na educação, é apresentado associado a uma visão de que a arte e a vivência das suas linguagens são facilitadoras da aprendizagem, silenciando a ideia de que ela significa um modo particular de compreender o mundo.

Essa visão denuncia uma perspectiva, ainda recorrente, de que a arte, na educação, é um caminho que serve para despertar interesse dos alunos a aprenderem conhecimentos socialmente mais valorizados. Tal postura afirma que, 
na arte, não há substrato suficiente para ela ser considerada como objeto de aprendizagem de sentido social e cultural. Tais concepções se referem às influências da psicologização da arte, enfatizada pelo processo de criação e vivência, conforme aparece no texto da ementa. A escolha desse vocabulário nos faz inferir a força de uma visão da psicologia, de cunho positivista, objetivista e a-histórico, na construção das bases da educação na modernidade, pautadas em ideias como as de criatividade como algo inato, conforme postulou Guilford (1975), ideólogo dos testes de criatividade.

Esses vestígios de uma "aprendizagem” em arte podem também trazer a marca de concepções escolanovistas, que, segundo Iavelberg (2003), receberam forte influência de estudos sobre a criatividade de pensadores como Lowenfeld e Brittain (1997), que compreendiam o ensino de arte baseado na livre expressão e no desenvolvimento da criatividade a partir da autoexpressão.

No Brasil, ressalta Iavelberg (2003), as teorias escolanovistas sofreram deformações em suas aplicações no ensino de arte, fazendo com que este fosse tomado como momento de relaxamento e expressão de sentimentos.

A ementa mencionada enfatiza o aspecto do ensino tomando a docência por base da formação do pedagogo, como defendido pelas DCN, valorizando o conteúdo pautado nos fundamentos da arte-educação.

Percebe-se uma articulação discursiva entre dois campos epistemológicos que, dialeticamente, corroboram a construção do significado do ensino de arte. Isso demonstra a historicidade do discurso, que absorve e é construído de textos do passado, como também reatualiza seus enunciados gerando novos textos (FAIRCLOUGH, 2001).

0 significado do ensino de arte produzido por esse discurso reflete a produtividade da luta hegemônica. Segundo Fairclough (2001), o evento discursivo tanto pode ser uma contribuição para preservar e reproduzir relações tradicionais quanto pode contribuir para transformar essas relações.
Nesse caso, a presença da concepção de arte como símbolo afetivo prejudica a tentativa de mudança social no que se refere ao ensino, tendo em vista que, histórica e ideologicamente, essa concepção vem prevalecendo nas práticas educativas.

Na ementa da disciplina Conteúdo e Metodologia do Ensino de Artes, do curso de Pedagogia da UEPB - Campus Campina Grande, observamos uma concepção que revela a caracterização dessa área com o mesmo valor que as demais áreas do conhecimento:

Caracterização da área de artes, concepções e abordagens que orientam o ensino de artes. Estudo de conteúdos de artes, para os anos iniciais do ensino fundamental e a análise crítica de livros e materiais didáticos. Propostas pedagógicas oficiais e alternativas. Orientações didáticas. A área de artes, e os temas transversais. (PPP/PEDAGOGIA/ UEPB, 2008 p. 60).

Destacamos o fato de que essa ementa valoriza a caracterização da área de arte, concepções e abordagens e o estudo de conteúdos como forma de enfatizar que a arte é um campo do conhecimento e, portanto, tem conteúdos específicos, como história da arte, política da arte, estética, estilo, produção artística e outros.

Nessa perspectiva, a ementa indica ser necessário discutir o que é arte, suas concepções e abordagens. A ênfase dada ao conteúdo da arte revela uma questão a ser considerada: a de que, em sua história, o ensino de arte no Brasil foi impregnado de uma crença, oriunda da livre expressão, de que arte tem forte característica emocional e, portanto, não há conteúdo a ser ensinado, o que, de certa forma, contribuiu para a sua desvalorização como conhecimento e da necessidade de profissionais capacitados.

Entretanto, de acordo com Penna e Nascimento (2001), se, por um lado, a ideia de uma espontaneidade infantil permeou práticas 
educativas em arte na escola a partir da concepção escolanovista, por outro, observamos a permanência da arte como decorativa, entendida simplesmente como útil para desenvolver habilidades manuais, ou lembrada para promover festas, culminâncias nas escolas, marcas de uma concepção romântica.

No curso de Pedagogia da UFCG Campus Campina Grande, a ementa da disciplina Arte na Educação Infantil e Anos Iniciais do Ensino Fundamental mostra-nos um pouco mais claramente a afirmação de uma concepção de arte como conhecimento, como linguagem.

Conceitos e princípios teóricos e metodológicos para o ensino da linguagem artística na Educação Infantil e nos Anos Iniciais do Ensino Fundamental. Especificidades da produção do conhecimento artístico em diferentes idades e contextos. Linguagens artísticas: integração entre os processos criativos, análise e contextualização. (PPP/ PEDAGOGIA,UFCG, p. 46-47)

As expressões linguagem artística e produção do conhecimento artístico indicam uma concepção contemporânea que concebe a arte como produto cultural presente na vida nas diferentes idades e contextos. Diferentemente das demais, essa ementa coloca em pauta questões teóricas e metodológicas para o ensino de arte e orienta que a compreensão das linguagens artísticas passa por uma integração entre processos criativos, análise e contextualização. Isso significa que o sujeito não é só instigado a se sensibilizar, mas também a pensar sobre os efeitos dessa sensibilização e situá-la em contextos históricos que envolvem valores sociais e culturais em sua produção.

Esse pensamento está pautado na "Proposta Triangular", que concebe a arte-educação como epistemologia da arte e/ou arte/educação como intermediária entre arte e público (BARBOSA, 2005a).
A integração entre processos criativos, análise e contextualização corresponde à educação do olhar e está de acordo com as orientações de Buoro (2003), ao ressaltar que o universo da educação do olhar, da visibilidade e da visualidade demonstra que esse domínio é um processo longo, lento e que envolve todos os sentidos. Ressalta, ainda, a importância do conhecimento sobre a história da arte para a compreensão da imagem no contexto de sua produção.

Nessa perspectiva, o ensino de arte é entendido como mediação cultural que vai além do desenvolvimento da sensibilidade, da criatividade, da percepção estética (universal), da criatividade, da fruição, da contemplação e da leitura formal da obra de arte. As finalidades do ensino tornam-se mais amplas e complexas, já que, nas tendências pedagógicas contemporâneas em arte-educação, exige-se uma potente mediação cultural, que vise superar as compreensões ingênuas da arte, as interpretações de senso comum, que, não raramente, são preconceituosas, a fim de alcançar o domínio do que Franz (2003) chama de compreensão crítica.

É importante salientar que, na atualidade, as mudanças no ensino de arte se apresentam como um caminho para estimular a consciência cultural do indivíduo, começando pelo reconhecimento da cultura local. Para isso, é necessário que as instituições educacionais deixem de ser meras transmissoras de conteúdos e passem a ser verdadeiras instituições sociais, ajudando os que passam por ela a olharem criticamente para o mundo do qual fazem parte como sujeitos históricos e como cidadãos (HERNÁNDEZ, 2000). Uma vez que a educação para a compreensão crítica, em última instância, visa a educação para a cidadania, é necessário situar as práticas de mediação entre arte e seus públicos em uma análise que explore as tão frequentemente ignoradas relações complexas entre conhecimento, poder e ideologia, em função das questões de gênero, classe, etnia, sexualidade, idade, entre outras, 
favorecendo o desenvolvimento e a potencialização das dimensões criativa, estética e cultural do ser humano.

\section{Considerações finais}

Através dos discursos analisados, evidenciamos, primeiramente, nas políticas de formação docente, o viés neoliberal, manifestando, através das DCN, a predominância da perspectiva da racionalidade técnica na construção da identidade do pedagogo, entendida como construto político produzido em práticas discursivas e legitimadas nas instituições e coletividades.

Outro aspecto revelado na pesquisa trata da ressignificação da teoria do capital humano na interpretação dos aspectos estéticos e criativos do sujeito, o qual evidencia a articulação entre educação e mercado de trabalho, vista de maneira pragmática, em que o profissional deve ter o conhecimento técnico para desempenhar sua função e, ao mesmo tempo, investir em habilidades exigidas pelo mercado ou aperfeiçoá-las.

Observamos que o texto analisado nas DCN demonstra, em seus elementos discursivos, a predominância da política neoliberal na construção da identidade do pedagogo, seu campo de atuação e suas competências. Consideramos que as DCN expressam uma política curricular na qual estão em jogo visões de mundo e onde se produzem narrativas e significados sobre os sujeitos, posicionando-os. Por essa razão, podemos afirmar que os discursos produzidos pelas DCN se constituem como uma política cultural cujo objetivo é o governo e a regulação social dos sujeitos a partir da construção de significados sociais e culturais hegemônicos.

Em relação à diversidade cultural, observamos também relações de poder, porquanto produz identidades culturais "desejadas", expondo a disputa pela imposição de determinados sentidos através da falsa ilusão de respeito à multiplicidade cultural. Ressaltamos, também, que os discursos sobre a diversidade cultural analisados perpassam uma compreensão ingênua das diferenças, escamoteando as relações de dominação que ocorrem nos processos culturais.

Nesse contexto, analisamos o lugar do ensino de arte nas políticas de formação docente, identificando as concepções que permeiam esse ensino nos currículos dos cursos de Pedagogia. Constatamos que há, ainda, muito a ser discutido, pois a Lei de Diretrizes e Bases, os PCN e as Diretrizes Curriculares, como documentos oficiais, representam discursos e ações dos profissionais da educação e, especificamente, da arte, os quais reivindicaram o compromisso do Estado com o processo de implementação do ensino de arte nas escolas. No entanto, suas concepções e modelos se apresentam descontextualizados, conservadores e equivocados no que diz respeito à formação docente.

Acreditamos que, diante da complexidade do ensino de arte na escolarização inicial, seria desejável uma atuação de professores de arte em parceria com o pedagogo. Esta seria uma experiência enriquecedora tanto para professores quanto, especialmente, para alunos e alunas. Porém, tal realidade, de maneira geral, não ocorre nas escolas de educação infantil e no ensino fundamental do nosso país (BARBOSA, 2005; FUSARI; FERRAZ, 2001), prejudicando o desenvolvimento da dimensão estética e artística de nossos estudantes, como proclamado pelos defensores de um ensino de arte que aponte para a multiplicidade do ser humano.

Ademais, se o professor-pedagogo mantiver, em sua formação, contato com a proposta do ensino de arte pautado nas contribuições contemporâneas, será possível desconstruir a visão predominante do senso comum de desvalorização da arte como conhecimento, de expressão emocional ou terapêutica, e construir uma educação do olhar que lhe possibilite compreender e apreciar as diferentes formas de expressão e manifestação das diversas culturas de maneira crítica e criativa. 
Nas concepções que permeiam as ementas das disciplinas destinadas ao ensino de arte nos currículos dos cursos de Pedagogia que foram analisados, percebemos construções epistemológicas distintas. Cada ementa apresentou, de forma clara, o processo histórico das transformações que o ensino de arte vem sofrendo nas últimas décadas, desde a permanência das influências do escolanovismo, do resgate do corpus teórico, até as contribuições contemporâneas.

A escolha epistemológica de cada ementa revela que não é somente com a inclusão da arte no currículo que estariam garantidos, de forma mágica, o crescimento individual e o comportamento dos cidadãos como construtores de sua própria história. Além de lhe reservar um lugar no currículo, é também necessário se preocupar como ela é concebida e ensinada. Essa constatação abre espaço para a sugestão de futuras pesquisas que abordem o significado do ensino de arte nas políticas de currículo, a atuação de pedagogos no ensino de arte e tantas outras que podem surgir a partir dessas análises.

Entendemos, portanto, que o professor-pedagogo, como sujeito, deve vivenciar, em sua formação profissional, uma educação artística não apenas em função das atividades de ensino, mas pela sua importância na formação integral do homem, na perspectiva da formação estética a partir da atividade criadora. Para que essa formação artística e cultural lhe seja garantida, apontamos, primeiramente, a necessidade de se tratar a arte como objeto de conhecimento. Consideramos importante também promover políticas de formação docente e assegurar a ampliação do acesso aos bens culturais e artísticos por meio da ampliação de políticas públicas para a cultura.

Ao analisarmos, aqui, o ensino da arte na formação do pedagogo, compreendemos que é preciso investir nessa formação na medida em que esse ensino, no curso de Pedagogia, além de contemplar os conteúdos pertinentes à educação infantil e ao ensino fundamental, deve proporcionar a compreensão da arte como mediação do processo formativo e instrumentalizar o aluno-pedagogo por meio da frequentação aos equipamentos artístico-culturais. Entretanto, não observamos de forma clara, nos currículos dos cursos, além das disciplinas, ações que viabilizassem tal mediação.

0 aluno-pedagogo, em seu cotidiano, deve ter oportunidades educativas por meio das quais possa entender a arte e favorecer a formação estética desses profissionais. Isso, no entanto, só será possível se o seu curso de formação proporcionar tais condições de aprendizagem. 


\section{Referências}

APPLE, Michael W. Repensando ideologia e currículo. In: MOREIRA, Antonio; SILVA, Tomaz Tadeu (Orgs.). Currículo, cultura e sociedade. São Paulo: Cortez, 1995, p. 7-35.

BAKTHIN, Mikhail. Marxismo e filosofia da linguagem. São Paulo: Hucitec, 1997.

BALL, Stephen J. Cidadania global, consumo e política educacional. In: SILVA, Luiz Heron (Org.). A escola cidadã no contexto da globalização. Petrópolis: Vozes, 1998, p. 121-137.

; BOWE, Richard. El currículum nacional y su "puesta en práctica": El papel de los departamentos de materias o asignaturas. Revista de Estudios de Currículum, Chile, v. 1, n. 2, p. 105-131, abr. 1998.

BARBOSA, Ana Mae. A imagem no ensino da arte. 6. ed. São Paulo: Perspectiva, 2005a.

(Org.). Arte/educação contemporânea: consonâncias internacionais. São Paulo: Cortez, 2005b.

BERNSTEIN, Basil. A estruturação do discurso pedagógico: classe, códigos e controle. Petrópolis: Vozes, 1996a.

BRASIL. Lei de Diretrizes e Bases da Educação Nacional. Lei nº 9.394, de 20 de dezembro de 1996.

BRASIL. Conselho Nacional de Educação. Conselho Pleno. Resolução $\mathbf{n}^{\mathbf{0}}$. 1, de 15 de maio de 2006, que institui as Diretrizes Curriculares Nacionais para o Curso de Graduação em Pedagogia, licenciatura.

BUORO, Anamélia Bueno. Olhos que pintam: a leitura da imagem e o ensino da arte. São Paulo: Educ; Fapesp; Cortez, 2003.

CANCLÍNI, Néstor García. Culturas híbridas: estratégias para entrar e sair da modernidade. 2. ed. São Paulo: Editora da Universidade de São Paulo, 1998.

COSTA, Marisa Vorraber. Currículo e política cultural. In: Janeiro: DP\&A, 1999, p. 37-65. (Org.). 0 currículo nos limiares do contemporâneo. Rio de

FAIRCLOUGH, Norman. Discurso e mudança social. Brasília: Universidade de Brasília, 2001.

FERRAZ, Maria Heloísa C. Toledo; FUSARI, Maria F. Rezende. Metodologia do ensino de arte - fundamentos e proposições. 2. ed. São Paulo: Cortez, 2009.

FRANZ, Terezinha Sueli. Educação para uma compreensão crítica da arte. Florianópolis: Letras Contemporâneas, 2003.

FUSARI, Maria F. Rezende; FERRAZ, Maria Heloísa C. Toledo. Arte na educação escolar. São Paulo: Cortez, 2001. (Coleção Magistério 2. grau, Série Formação Geral.)

GENTILI, Pablo. Políticas educacionais no contexto do neoliberalismo: os significados da privatização no campo educacional. In: OLIVEIRA, Maria Neusa de. As políticas educacionais no contexto da globalização. Ilhéus: Editus, 1999.

. A falsificação do consenso: simulacro e imposição na reforma educacional do neoliberalismo. Petrópolis: Vozes, 1998.

GRAMSCI, Antonio. Os intelectuais e a organização da cultura. 5. ed. Rio de Janeiro: Civilização Brasileira, 1989.

GUILFORD, Joy Paul. Traits of creativity. In: VERNON, Philip E. (Org). Creativity. Harmondsworth: Penguin, 1975.

HALL, Stuart. A centralidade da cultura: notas sobre as revoluções de nosso tempo. Educação \& Realidade, v. 22, n. 2, p. 15 46, jan./jun. 1997.

HERNÁNDEZ, Fernando. Cultura visual, mudança educativa e projetos de trabalho. Porto Alegre: Artes Médicas, 2000. 
IAVELBERG, Rosa. Para gostar de aprender arte: sala de aula e formação de professores. Porto Alegre: Artmed, 2003.

LOWENFELD, Viktor; BRITTAIN, W. Lambert. Desenvolvimento da capacidade criadora. São Paulo: Mestre Jou, 1977.

MACEDO, Elizabeth. Currículo como espaço-tempo de fronteira. Revista Brasileira de Educação. Caxambu: Autores Associados; Anped, n. 32 mai./ago. 2006a, p. 286-295.

Currículo: política, cultura e poder. Currículo sem Fronteiras, v. 6, n. 2, p. 98-113, jul./dez. 2006b. Disponível em: www. curriculosemfronteiras. org.> Acesso em: 30/07/2009.

MOITA LOPES, Luiz Paulo da. Socioconstrucionismo: discurso e identidades sociais. In: Discursos de identidades. Campinas: Mercado de Letras, 2003, p. 13-38.

PENNA, Maura; NASCIMENTO, Erinaldo Alves. Marcas do romantismo: os impasses da fundamentação dos PCN-Arte. In: PENNA, Maura (Coord.). É esse o ensino de arte que queremos? Uma análise das propostas dos Parâmetros Curriculares Nacionais. João Pessoa: Universitária; CCHLA; PPGE, 2001.

PREFEITURA MUNICIPAL DE JOÃO PESSOA. Sistema Municipal de Ensino. Conselho Municipal de Educação. Resolução nº 009 , de 11 de dezembro de 2006, que institui a implantação do ensino de artes em todas as séries e modalidades nos níveis infantil e fundamental.

SILVA, Tomaz Tadeu da (Org.). Identidade e diferença: a perspectiva dos estudos culturais. Petrópolis: Vozes, 2000.

TOURINHO, Irene. Transformações no ensino da arte: algumas questões para reflexão conjunta. In: BARBOSA, Ana Mae (Org.). Inquietações e mudanças no ensino da arte. 3. ed. São Paulo: Cortez, 2007.

WODAK, Ruth. De qué trata el análisis crítico del discurso. Resumen de su historia, sus conceptos fundamentales y sus desarrollos. In: WODAK, Ruth; MEYER, Michel (Orgs.). Métodos de análisis crítico del discurso. Barcelona: Gedisa, 2003, p. 17-34.

Recebido em: 26.06.2010

Aprovado em: 23.11.2010

Janedalva Pontes Gondim é professora da Universidade do Vale do São Francisco.

Ângela Maria Dias Fernandes é professora do Departamento de Psicologia e do Programa de Pós-graduação em Educação da Universidade Federal da Paraíba. E-mail: angeladfernandes@yahoo.com.br. 